This article is licensed under the Creative Commons Attribution-NonCommercial 4.0 International License (CC BY-NC) (http://www.karger.com/Services/OpenAccessLicense) Usage and distribution for commercial purposes requires written permission.

\title{
Effects of Arsenic Trioxide on Minor Progressive High-Grade Osteosarcoma of the Extremities Metastatic to the Lung: Results of 39 Patients Treated in a Single Institution
}

\author{
Lu Xie Wei Guo Xiaodong Tang Yi Yang Jie Xu
}

Musculoskeletal Tumor Center, Peking University People's Hospital, Beijing, China

\section{Keywords}

Osteosarcoma, minor progressive $\cdot$ Arsenic trioxide $\cdot$ Pulmonary metastasis

\section{Abstract}

Patients who mildly progressed after first-line chemotherapy were administered arsenic trioxide (ATO) 5-10 mg intravenously daily. Thirty-nine patients were finally enrolled in the study, of whom 19 patients received first-line chemotherapy with ATO infusion while 20 patients did not. Progression-free survival at 4 months was 89.2 and $62.7 \%(p=0.043)$ for the ATO group and the control group, respectively, while the 2-year overall survival was 61 and $16.4 \%$ $(p=0.032)$. 


\section{Case Reports in Oncology}

\section{Introduction}

Following the implementation of chemotherapy in the 1970s, treatment of high-grade osteosarcoma has made great progress. Modern, multiagent, dose-intensive chemotherapy in conjunction with surgery achieves a 5-year overall survival (OS) of $60-70 \%$ in localized patients suffering from osteosarcoma of the extremities [1]. However, a major, as yet unsolved, problem is the poor prognosis for refractory metastatic or recurrent disease, with a 5-year OS of $18-33 \%$ [1-4].

The role of lung metastasectomy was affirmed for a couple of years especially for people with resectable pulmonary metastasis [5-9]. These patients should be addressed in a multidisciplinary fashion, involving a thoracic surgeon with experience in pulmonary metastasectomy. It was discovered that patients with survival benefit all had complete surgical removal of metastatic tumors, whereas those who were not operated on or who had partial removal did not survive. The definition of 'resectable' relies on the opinion of the thoracic surgeons. Early clinical intervention in the case of newly found metastatic lesions is thought to be crucial and effective for better prognosis [9]. During conventional chemotherapy, it is always difficult for clinicians to decide whether to change the first-line chemotherapy or not, when bilateral multiple metastatic pulmonary lesions firstly emerge with a maximal size of 3-5 $\mathrm{mm}$, which we defined as minor progressive disease. At this stage, those multiple minor lesions might be difficult to locate, and thoracotomy with manual palpation may be a huge trauma to patients without complete resection. Changing the systemic protocol to secondline chemotherapy may not be as effective as the first-line therapy. Today, most oncologists choose to continue with the first-line chemotherapy and wait for the appropriate opportunity, when the lesions grow, to transfer these patients to thoracic surgery, or if the lesions grow worse, to second-line protocol or clinical trials.

Arsenic trioxide (ATO, $\mathrm{As}_{2} \mathrm{O}_{3}$ ) has been studied and used for thousands of years for Chinese people as a traditional oriental medicine. Today, it is associated with substantial clinical efficacy in the treatment of promyelocytic leukemia patients [10-15]. In addition, preclinical studies have shown that other hematological cancers and solid tumors are susceptible to ATO [16-19]. Although the exact mechanisms underlying the antitumor effects of this agent remain unclear, ATO has been recognized as a powerful inducer of oxidative stress in tumor cells [20]. Some scholars consider low-dose ATO as a immunomodulator that could increase antitumor immune response in colon tumor-bearing mice by modulating regulatory T-cell (Treg) abundance [21]. Based on those findings and our preclinical data on osteosarcoma cells $[22,23]$, we conducted and observed the immunostimulatory effects of low ATO concentrations combined with conventional chemotherapy in minor progressive osteosarcoma patients.

\section{Materials and Methods}

\section{Patients}

From March 1998 to December 2014, 775 consecutive patients with histologically proven high-grade osteosarcoma of the extremities were diagnosed and received treatment at the Musculoskeletal Tumor Center of Peking University People's Hospital. Of those 775 pa- 


\section{Case Reports in Oncology}

Xie et al.: Effects of Arsenic Trioxide on Minor Progressive High-Grade Osteosarcoma of the Extremities Metastatic to the Lung

tients (fig. 1), 124 had pulmonary metastasis: 70 patients had a metastatic lesion at presentation and 54 developed metastasis during/after treatment (within 6 months). The diagnosis of osteosarcoma was always made by histological examination of specimens taken from an open biopsy or a core needle biopsy. All patients underwent clinical routine evaluation including radiography, $\mathrm{CT}$ and/or MRI for an assessment of the primary tumor, as well as a chest CT scan and a radionuclide total bone scan to detect pulmonary and osseous metastasis. The diagnosis of pulmonary metastasis was based on chest CT, usually with high resolution. Still, we are aware that the results might be false positive, just as with other tumor types, because not all nodules shown on chest CT regardless of nodule size and number are metastatic lesions. We still consider it to be a rare event unless there is pathological evidence excluding it.

Eligible patients had the following characteristics: diagnosis of high-grade osteosarcoma confirmed histologically; no metastatic lesion shown on chest CT and bone scan/PET/CT at presentation; no previous treatments; an Eastern Cooperative Oncology Group performance status $\leq 2$; adequate renal, hepatic, and hematopoietic function; during evaluation, newly found bilateral multiple ( $\geq 3$ ) pulmonary nodules with a maximal nodule of 3-5 mm (defined as 'minor progressive' disease), and radiological evidence of disease progression found during first-line chemotherapy or within 6 months after chemotherapy. The definition of resectable or unresectable pulmonary lesions is made by thoracic surgeons, orthopedic oncologic surgeons, and oncologists. We excluded those patients who had metastases at other sites and whose metastatic lesions were considered for complete resection by thoracic surgeons.

\section{Treatment}

All patients received standard chemotherapy and surgery (limb salvage surgery or amputation). Though surgical techniques for local treatment and thoracic surgical techniques for pulmonary lesions may have changed over the last decades, achieving wide surgical margins was always assured as the primary goal. Current standard management comprises preoperative (neoadjuvant) chemotherapy followed by surgical removal of local disease and postoperative (adjuvant) chemotherapy (fig. 2). Supplemental therapeutic approaches are angioembolization, chemotherapy using intra-arterial infusion, gamma knife radiosurgery of the pulmonary metastatic lesion, and others. First-line chemotherapy agents include: high-dose methotrexate with leucovorin rescue, doxorubicin (adriamycin), cisplatin, and ifosfamide (for a detailed regimen, see fig. 2). Those patients who met with inclusion criteria were administered ATO 5-10 mg (usually adults were given $10 \mathrm{mg}$ daily, while children $<10$ years with a body weight $<30 \mathrm{~kg}$ were given $5 \mathrm{mg}$ daily) intravenously daily for 28 days/cycle (fig. 2). During observation, if the disease was still progressive, the patient would be withdrawn from the ATO infusion and was recommended lung metastasectomy (if possible), to receive second-line chemotherapy, or directly join clinical trials. For most of the patients, surgeons and pathologists reviewed gross specimens and histological material to determine the surgical margins after surgery. Histological evaluation of the primary tumor response was performed according to a method previously reported [24]. A tumor necrosis rate $\geq 90 \%$ was defined as 'good' and a tumor necrosis rate $<90 \%$ as 'poor', according to the literature [25]. 


\section{Case Reports in Oncology}

Case Rep Oncol 2016;9:610-628
\begin{tabular}{l|l}
\hline DOI: 10.1159/000448705 & $\begin{array}{l}\text { C } 2016 \text { The Author(s). Published by S. Karger AG, Basel } \\
\text { www.karger.com/cro }\end{array}$
\end{tabular}

Xie et al.: Effects of Arsenic Trioxide on Minor Progressive High-Grade Osteosarcoma of the Extremities Metastatic to the Lung

\section{Efficacy Assessment}

Before starting treatment, patients were staged with chest CT of high-resolution layer, bone scan or PET/CT, as well as with localized CT and/or MRI. Baseline assessment contained full blood count, serum chemistry, physical inspection, and relevant examination of the heart and respiration. During chemotherapy, all those tests were repeated every 8 weeks unless there were toxic effects or suspicion of disease progression. The focus of this study was progression-free survival (PFS) and clinical benefit rate (CBR). Response was assessed by CT scan, mostly according to RECIST $1.0[26,27]$; however, since our lesions were too small to observe a significant change in size during reevaluation intervals (8 weeks), we consider both a newly detected lesion or a volume increase by $\geq 50 \%$ as progressive disease and a volume decrease by $\geq 50 \%$ as partial response (PR). Complete response (CR) and PR needed confirmation within 4 weeks after a response was first demonstrated. Stable disease (SD) was confirmed after at least 8 weeks. CBR was defined as a PFS rate (CR + PR + SD) of $\geq 6$ months. Duration of response was calculated from the day of first response assessment until either progression/death or last follow-up (censored). OS was calculated from the date of pulmonary recurrence to the time of last follow-up or death, while PFS was calculated from the detection of metastasis to disease progression or follow-up. PFS, OS, and duration of response were estimated according to the Kaplan-Meier method with their interquartile range (IQR). Another notable parameter was disease-free interval, which means the interval from diagnostic biopsy to first pulmonary metastasis.

\section{Statistics}

All parameters were first investigated by univariate techniques. The $\chi^{2}$ analysis was used to compare unrelated samples. Survival analyses were performed using the KaplanMeier method [28]. The log-rank test was used to compare survival curves [29]. Because of the small sample, univariate analyses of survival were used to compare different parameters and completed using the Cox proportional hazards model [30]. All p values were two-sided, and a $p$ value $<0.05$ was significant.

\section{Results}

\section{Features of the Study Population}

Among the 39 eligible patients, there were 22 males (56.4\%) and 17 females (43.6\%) (table 1). At initial diagnosis, the median age of all eligible patients was 17 years (range 655). Until the last follow-up on March 1st, 2015, 1 patient was alive without evidence of disease, 20 patients were alive with disease, and 18 patients had died from the tumor. 19 patients received first-line chemotherapy together with long-term ATO infusion while 20 patients had first-line chemotherapy alone. The median follow-up time was 9.3 months (range 2-46; IQR 3.2-21.8).

The most common primary site of tumor was the distal femur $(n=20)$, followed by the proximal tibia and/or fibula $(n=8)$, proximal humerus $(n=4)$, and proximal femur $(n=4)$. The remaining 3 patients had tumors located in the scapula, distal tibia, and metacarpus. 31 patients had conventional osteosarcoma, which included the osteoblastic, chondroblastic, and fibroblastic type. Two patients had telangiectatic osteosarcoma, 5 patients had small cell 


\section{Case Reports in Oncology}

Xie et al.: Effects of Arsenic Trioxide on Minor Progressive High-Grade Osteosarcoma of the Extremities Metastatic to the Lung

type carcinoma, and 1 patient had mixed-type osteosarcoma. Of all those patients, 16 $(41.0 \%)$ had a tumor necrosis rate $\geq 90 \%$ after surgery of the local lesion, and $8(20.5 \%)$ had tumor necrosis $<90 \%$, while the data of 15 patients were missing or not available for analysis.

\section{Prognostic Factors and Survival}

PFS at 4 months was 89.2 and $62.7 \%(p=0.043)$ for the ATO group and the control group (fig. 3), respectively, while the 2-year OS was 61.0 and $16.4 \%$ ( $p=0.032$ ) (fig. 4, fig. 5). The median time to progression for patients with and without ATO infusion was 10.2 months (IQR 6.5-24.3) and 5.9 months (IQR 3.4-9.9), respectively. At the same time, we noticed that the median follow-up time for patients receiving first-line chemotherapy with and without ATO was 29.4 months (IQR 11.2-31.4) and 12.8 months (IQR 8.4-24.5), respectively. For patients with ATO infusion, we observed 2 (10.5\%) CRs, 3 (15.8\%) PRs, 13 (68.4\%) SD, and $1(5.3 \%)$ progressive disease. And for 13 patients (68.4\%), the clinical benefit (CR + PR + SD) lasted longer than 6 months. Meanwhile, for the control group, 10 (50\%) patients had SD, and 10 (50\%) had disease progression with CBR 30\% (6 patients) (fig. 6).

Comparing all those clinicopathological parameters that might affect PFS, we noticed that the location of the primary tumor $(p=0.014)$, the chemotherapy scheme $(p=0.043)$, and the disease-free interval ( $p=0.012)$ obviously influenced survival. Age $(p=0.193)$, gen$\operatorname{der}(p=0.475)$, pathological subtype $(p=0.106)$, tumor necrosis rate $(p=0.091)$, and local recurrence $(p=0.511)$ did not seem to be connected with obvious different survival (table 1). The median interval (disease-free interval) from the start of treatment for the primary tumor to first metastasis was 5.3 months (IQR 1.5-9.8) (for details, see table 1)

\section{Chemotherapy Toxicity}

In total, 132 cycles of chemotherapy were performed. Nearly one third of the patients had chemotherapy delayed by $>1$ week due to delayed bone marrow recovery, abnormal laboratory findings (mainly elevated hepatic enzymes), surgical complications, delayed clearance of methotrexate, or other problems. The ATO-combined chemotherapy was well tolerated, and approximately $30 \%$ of patients had grade 3 or 4 adverse events. The most obvious manifestation was that ATO could aggravate myelosuppression, and nearly all those patients complained of longer intervals of rehabilitation, with 3 patients experiencing grade 4 myelosuppression. Frequent adverse events included nausea and emesis, diarrhea, fatigue, neuropathy, and others, all of which could be tolerated by symptomatic treatment. Only 1 patient turned up with persistent abdominal pain with derma and nail hyperpigmentation, and she was found to have an internal arsenic concentration $>10 \mu \mathrm{mol} / \mathrm{l}$ (normal: <2 $\mu \mathrm{mol} / \mathrm{l})$. She had to stop treatment because of chronic arsenic poisoning, and the arsenic content distribution gradually reverted to normal after 2 months.

\section{Discussion}

At the time of osteosarcoma diagnosis, about $10-20 \%$ of patients presented with macroscopic evidence of metastatic disease, most commonly in the lungs, then in bones, and rarely

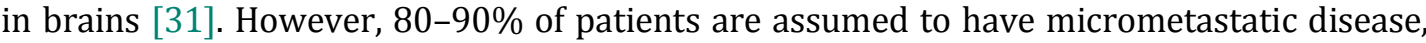




\section{Case Reports in Oncology}

Xie et al.: Effects of Arsenic Trioxide on Minor Progressive High-Grade Osteosarcoma of the Extremities Metastatic to the Lung

which is subclinical or undetectable using current diagnostic modalities [32]. A total of 30$40 \%$ of patients with localized osteosarcoma will develop local recurrence or distant metastasis [33]. Approximately $90 \%$ are pulmonary metastases, which usually occur in the first 23 years after diagnosis [7] and are associated with a rather poor prognosis. The 5-year OS for those with lung metastasis has been reported to be 19.1-37\% [34, 35] (table 2).

Aggressive multimodal therapy holds the promise to achieve prolonged survival, especially in patients who respond well to chemotherapy [6, 7]. Recently, the most commonly recognized chemotherapy regimens applied for osteosarcoma have been based on 4 drugs: high-dose methotrexate with leucovorin rescue, doxorubicin (adriamycin), cisplatin, and ifosfamide [1], and these agents were integrated into various chemotherapy protocols. Our center has been using these drugs following the protocol (fig. 2) since 1997, and the oncologic outcome of OS patients was almost in accordance with that reported in the literature [1, $32,36]$. However, for those osteosarcoma cases with synchronous or metachronous pulmonary metastasis, there is no standardized therapeutic strategy, though most protocols included general recommendations. Resection of pulmonary metastasis from osteosarcoma is a treatment option which has been shown to correlate with survival benefit and cure in select individuals. Although not conclusive, the wealth of retrospective data support surgical resection of pulmonary metastasis in carefully selected patients. It seems that the primary selection criteria that should be considered is the ability to achieve a complete resection. From all those large trials (table 2) and the present study, we could found that macroscopic complete resection correlated with improved survival. However, for unresectable patients, thoracotomy could not improve survival but brought more suffering.

Early clinical intervention to newly found metastatic lesions is thought to be crucial and effective for better prognosis. During conventional chemotherapy, it is always difficult for clinicians to decide whether to change first-line cheomtherapy or not when bilateral multiple ( $\geq 3$ ) metastatic pulmonary lesions firstly emerge with a maximal size of 3-5 mm, which we defined as minor progressive disease. It is considered difficult for thoracic surgeons to locate and remove all the lesions, while changing the systemic protocol to second-line chemotherapy may not be as effective as first-line chemotherapy. Presently, with the development of a recognition of the monocyte/macrophage immunomodulator muramyl tripepetide phosphatidylethanolamine [3], OS of osteosarcoma seems to increase when combined with standard chemotherapy, while more recent results of clinical trials have shown no improvement in the last 30 years and deserve further investigation [37]. However, antitumor immunotherapy has become a hotspot when biological and immunological agents are under investigation in preclinical or clinical trials. Thus, new therapeutic tools are awaited.

Mentioning ATO, many people think of its use as an antileukemia agent dating back to the late 19th century, which was only replaced by modern chemotherapeutics in the 1950s [38]. Although the exact mechanisms underlying the antitumor effects of this agent remain unclear, ATO has been recognized as a powerful drug with clinical benefit not only in acute promyelocyctic leukemia, but also in other solid tumors [39]. Nowadays, some scholars tend to consider it inhibiting osteosarcoma cell invasiveness via the MAPK signaling pathway [22]. Thomas-Schoemann et al. [22] observed immunostimulatory effects at low $\mathrm{As}_{2} \mathrm{O}_{3}$ concentrations $(0.5-1 \mu \mathrm{M})$ in vitro and with a single $1-\mathrm{mg} / \mathrm{kg}$ dose in vivo [40]. The immunogenic effects of low-dose ATO appeared to be related to the high sensitivity of Tregs to this agent, which killed those cells by oxidative stress and nitrosative bursts; thus, the antitumor 


\section{Case Reports in Oncology}

activity of effector T cells could be improved because of the depletion of Tregs [20]. The immunomodulatory mechanisms of ATO have been proven and observed in colon and breast cancer cell experiments $[20,21]$. These positive results, along with our preclinical data [22, 41], provided the background for the design of our study, in which ATO was added to conventional first-line chemotherapy to observe the clinical effects of this agent on minor progressive osteosarcoma.

The outcome of the study astonished us: PFS at 4 months of targeted patients was $89.2 \%$ with obvious statistical benefit $(\mathrm{p}=0.043$ ) compared to that of the control group, which was $62.7 \%$ (fig. 5). The 2-year OS differed more distinctly ( 61 and $16.4 \% ; \mathrm{p}=0.032$ ). The median time to progression for patients receiving ATO and that in the control group was 10.2 (IQR 6.5-24.3) and 5.9 (IQR 3.4-9.9), respectively. Though it was a small sample study, from the detailed response figure (fig. 7) that we made according to these data, we could deduce that this difference should be more obvious with a larger sample. The CBR was $68.4 \%$. We observed 2 (10.5\%) CRs, 3 (15.8\%) PRs, 13 (68.4\%) SD, and 1 (5.3\%) progressive disease. Within this context, ATO produced two notable results. Firstly, it achieved a far greater PFS at 4 months than the hypothesized threshold of interest, and, secondly, it delivered a CBR of more than half of the patients with progressive disease at enrollment. We are aware of the fact that our patients were in an early phase of disease progression and thus the PFS might be longer than that traditionally defined as 'refractory' disease. However, this PFS interval was worthy of attention, compared with the literature [5, 9, 31, 42], and the outcome was superior to our own historical control.

Although this study was a retrospective case series report, we did find that for those nodules $<5 \mathrm{~mm}$, adding ATO to conventional chemotherapy could make the lesions shrink (case shown in fig. 7), which indicates that those who already seemed to be drug resistant to first-line chemotherapy might continue to benefit from those drugs when ATO was added. We considered this early intervention as effective. Whether those people profited from the chemotherapy or ATO is a problem which needs to be verified urgently. And, it is suspected that ATO may intrigue autoimmunology targeted on tumor cells by depleting Tregs through oxidative and nitrosative bursts [20]. We did observe some long-lasting disease stability. Whereas in a nonrandomized study [42-45], such behavior could be attributed to tumor growth variability rather than to study agent activity, physicians involved in the care of highgrade osteosarcoma patients would estimate the likelihood of 'spontaneous' stability to be extremely low. Still, the phenomenon that most of those baseline progressive lesions have shrunk or were calcified when ATO was added at least demonstrated some potential for further research of ATO in osteosarcoma.

In some cases, tumor shrinkage may not be obvious or may even occur together with lesion calcification, while density reduction on the CT scan or the SUV $\max$ uptake of PET/CT may be a relatively new type of radiological finding for the evaluation of chemo-response [46]. From this point of view, such objective findings of dimensional response might not represent proof for all antitumor activities of this new agent [47]. Therefore, we believed SD (at least for 8 weeks) should be regarded as success of treatment in this specific population, and, thus, ATO could be considered efficacious in our study.

We acknowledge that our study has some limitations due to its retrospective case series nature and lack of a larger sample to demonstrate statistical significance. At the same time, some patients were lost to follow-up because of various reasons and maybe we had some 


\section{Case Reports in Oncology}

\begin{tabular}{l|l}
\hline Case Rep Oncol 2016;9:610-628 \\
\hline DOI: 10.1159/000448705 & $\begin{array}{l}\text { (C) 2016 The Author(s). Published by S. Karger AG, Basel } \\
\text { www.karger.com/cro }\end{array}$
\end{tabular}

Xie et al.: Effects of Arsenic Trioxide on Minor Progressive High-Grade Osteosarcoma of the Extremities Metastatic to the Lung

selection bias regarding the study population. Yet, we conceived this study to explore a completely different strategy in the treatment of refractory metastatic osteosarcoma. Compared to other immunomodulators, such as MTP-PE, it is quite cheap and convenient. Unlike those membrane tyrosine kinase receptor inhibitors, this agent could be stopped at any time without significant 'rebound' of the tumor. Its advantages deserve further investigation in prospective clinical trials.

The combination of ATO and chemotherapy was well tolerated, and approximately $30 \%$ patients had grade 3 or 4 adverse events. The most obvious manifestation was that ATO could aggravate myelosuppression, and nearly all patients complained of longer intervals of rehabilitation. Frequent adverse events included nausea and emesis, diarrhea, fatigue, neuropathy, as well as others. Chronic arsenic poisoning should be looked for when patients received more than 4 cycles of infusion. It did happen rarely, depending on individual physical differences. However, usually, after stopping the drug for 2 months or longer, the arsenic content distribution did gradually revert to normal.

\section{Conclusion}

Early intervention using low-dose ATO combined with first-line chemotherapy displayed obvious clinical effects and an acceptable toxicity in minor progressive osteosarcoma patients, and thus, these encouraging results call for further prospective randomized controlled trials.

\section{Acknowledgements}

We thank Tao Ji who provided genuine suggestions for this paper and Rongli Yang for his great substantial contributions to the conception, design, and acquisition of data. We are also grateful to Xiao Li for his interpretation of data.

\section{Statement of Ethics}

The authors have no ethical conflicts to disclose.

\section{Disclosure Statement}

The authors have no conflicts of interest to declare. 


\section{Case Reports in Oncology}

Case Rep Oncol 2016;9:610-628

DOI: $10.1159 / 000448705$

(C) 2016 The Author(s). Published by S. Karger AG, Basel www.karger.com/cro

Xie et al.: Effects of Arsenic Trioxide on Minor Progressive High-Grade Osteosarcoma of the Extremities Metastatic to the Lung

\section{References}

1 Luetke A, Meyers PA, Lewis I, Juergens H: Osteosarcoma treatment - where do we stand? A state of the art review. Cancer Treat Rev 2014;40:523-532.

Jaffe N, Puri A, Gelderblom H: Osteosarcoma: evolution of treatment paradigms. Sarcoma 2013;2013:203531.

3 Meyers PA, Chou AJ: Muramyl tripeptide-phosphatidyl ethanolamine encapsulated in liposomes (LMTP-PE) in the treatment of osteosarcoma. Adv Exp Med Biol 2014;804:307-321.

-4 Whelan JS, Bielack SS, Marina N, Smeland S, Jovic G, Hook JM, Krailo M, Anninga J, Butterfass-Bahloul T, Bohling T, Calaminus G, Capra M, Deffenbaugh C, Dhooge C, Eriksson M, Flanagan AM, Gelderblom H, Goorin A, Gorlick R, Gosheger G, Grimer RJ, Hall KS, Helmke K, Hogendoorn PC, Jundt G, Kager L, Kuehne T, Lau C, Letson GD, Meyer J, Meyers P, Morris C, Mottl H, Nadel H, Nagarajan R, Randall RL, Schomberg P, Schwarz R, Teot LA, Sydes MR, Bernstein M; on behalf of the EURAMOS collaborators: EURAMOS-1, an international randomised study for osteosarcoma: results from pre-randomisation treatment. Ann Oncol 2015;26:407-414.

5 Matsumoto I, Oda M, Yachi T, Tsuchiya H, Zen Y, Watanabe G: Outcome prediction of pulmonary metastasectomy can be evaluated using metastatic lesion in osteosarcoma patients. World J Surg 2013;37:1973-1980.

Briccoli A, Rocca M, Salone M, Guzzardella GA, Balladelli A, Bacci G: High grade osteosarcoma of the extremities metastatic to the lung: long-term results in 323 patients treated combining surgery and chemotherapy, 1985-2005. Surg Oncol 2010;19:193-199.

7 Bacci G, Rocca M, Salone M, Balladelli A, Ferrari S, Palmerini E, Forni C, Briccoli A: High grade osteosarcoma of the extremities with lung metastases at presentation: treatment with neoadjuvant chemotherapy and simultaneous resection of primary and metastatic lesions. J Surg Oncol 2008;98:415-420.

Bacci G, Briccoli A, Longhi A, Ferrari S, Mercuri M, Faggioli F, Versari M, Picci P: Treatment and outcome of recurrent osteosarcoma: experience at Rizzoli in 235 patients initially treated with neoadjuvant chemotherapy. Acta Oncol 2005;44:748-755.

-9 Steliga M, Vaporciyan A: Surgical treatment of pulmonary metastases from osteosarcoma in pediatric and adolescent patients. Cancer Treat Res 2009;152:185-201.

10 Sui M, Zhang Z, Zhou J: Inhibition factors of arsenic trioxide therapeutic effects in patients with acute promyelocytic leukemia. Chin Med J 2014;127:3503-3506.

11 Efficace F, Mandelli F, Avvisati G, Cottone F, Ferrara F, Di Bona E, Specchia G, Breccia M, Levis A, Sica S, Finizio O, Kropp MG, Fioritoni G, Cerqui E, Vignetti M, Amadori S, Schlenk RF, Platzbecker U, Lo-Coco F: Randomized phase III trial of retinoic acid and arsenic trioxide versus retinoic acid and chemotherapy in patients with acute promyelocytic leukemia: health-related quality-of-life outcomes. J Clin Oncol 2014;32:3406-3412.

12 Wang H, Cao F, Li J, Li L, Li Y, Shi C, Lan W, Li D, Zhao H, Zhang Y, Zhang Z, Liu X, Meng R, Yang B, Zhou J: Arsenic trioxide and mannitol for the treatment of acute promyelocytic leukemia relapse in the central nervous system. Blood 2014;124:1998-2000.

13 Zhu HH, Wu DP, Jin J, Li JY, Ma J, Wang JX, Jiang H, Chen SJ, Huang XJ: Oral tetra-arsenic tetra-sulfide formula versus intravenous arsenic trioxide as first-line treatment of acute promyelocytic leukemia: a multicenter randomized controlled trial. J Clin Oncol 2013;31:4215-4221.

14 Chen L, Wang J, Hu X, Xu X: Meta-analysis of all-trans retinoic acid-linked arsenic trioxide treatment for acute promyelocytic leukemia. Hematology 2014;19:202-207.

15 Lo-Coco F, Avvisati G, Vignetti M, Thiede C, Orlando SM, Iacobelli S, Ferrara F, Fazi P, Cicconi L, Di Bona E, Specchia G, Sica S, Divona M, Levis A, Fiedler W, Cerqui E, Breccia M, Fioritoni G, Salih HR, Cazzola M, Melillo L, Carella AM, Brandts CH, Morra E, von Lilienfeld-Toal M, Hertenstein B, Wattad M, Lubbert M, Hanel M, Schmitz N, Link H, Kropp MG, Rambaldi A, La Nasa G, Luppi M, Ciceri F, Finizio O, Venditti A, Fabbiano F, Dohner K, Sauer M, Ganser A, Amadori S, Mandelli F, Dohner H, Ehninger G, Schlenk RF, Platzbecker U; Gruppo Italiano Malattie Ematologiche dell'Adulto, German-Austrian Acute Myeloid Leukemia Study Group, Study Alliance Leukemia: Retinoic acid and arsenic trioxide for acute promyelocytic leukemia. N Engl J Med 2013;369:111-121.

16 Diepart C, Karroum O, Magat J, Feron O, Verrax J, Calderon PB, Gregoire V, Leveque P, Stockis J, Dauguet $\mathrm{N}$, Jordan BF, Gallez B: Arsenic trioxide treatment decreases the oxygen consumption rate of tumor cells and radiosensitizes solid tumors. Cancer Res 2012;72:482-490. 
Xie et al.: Effects of Arsenic Trioxide on Minor Progressive High-Grade Osteosarcoma of the Extremities Metastatic to the Lung solid tumor cells. Oncol Res 2009;18:83-94. Griffin RJ, Williams BW, Park HJ, Song CW: Preferential action of arsenic trioxide in solid-tumor microenvironment enhances radiation therapy. Int J Radiat Oncol Biol Phys 2005;61:1516-1522. Baumgartner M, Sturlan S, Roth E, Wessner B, Bachleitner-Hofmann T: Enhancement of arsenic trioxide-mediated apoptosis using docosahexaenoic acid in arsenic trioxide-resistant solid tumor cells. Int J Cancer 2004;112:707-712.

20 Thomas-Schoemann A, Batteux F, Alexandre J: A new strategy to target regulatory T cells in solid tumors. Oncoimmunology 2013;2:e23338.

21 Thomas-Schoemann A, Batteux F, Mongaret C, Nicco C, Chereau C, Annereau M, Dauphin A, Goldwasser F, Weill B, Lemare F, Alexandre J: Arsenic trioxide exerts antitumor activity through regulatory T cell depletion mediated by oxidative stress in a murine model of colon cancer. J Immunol 2012;189:51715177. Tingting R, Wei G, Changliang P, Xinchang L, Yi Y: Arsenic trioxide inhibits osteosarcoma cell invasiveness via MAPK signaling pathway. Cancer Biol Ther 2010;10:251-257.

-23 Yang GF, Li XH, Zhao Z, Wang WB: Arsenic trioxide up-regulates Fas expression in human osteosarcoma cells. Chin Med J 2010;123:1768-1773.

24 Picci P, Bacci G, Campanacci M, Gasparini M, Pilotti S, Cerasoli S, Bertoni F, Guerra A, Capanna R, Albisinni U, et al: Histologic evaluation of necrosis in osteosarcoma induced by chemotherapy. Regional mapping of viable and nonviable tumor. Cancer 1985;56:1515-1521. Huvos AG: Osteosarcoma in adolescents and young adults: new developments and controversies. Commentary on pathology. Cancer Treat Res 1993;62:375-377.

-26 Duffaud F, Therasse P: New guidelines to evaluate the response to treatment in solid tumors. Bull Cancer 2000;87:881-886.

27 Therasse P, Arbuck SG, Eisenhauer EA, Wanders J, Kaplan RS, Rubinstein L, Verweij J, Van Glabbeke M, van Oosterom AT, Christian MC, Gwyther SG: New guidelines to evaluate the response to treatment in solid tumors. European Organization for Research and Treatment of Cancer, National Cancer Institute of the United States, National Cancer Institute of Canada. J Natl Cancer Inst 2000;92:205-216. Dinse GE, Lagakos SW: Nonparametric estimation of lifetime and disease onset distributions from incomplete observations. Biometrics 1982;38:921-932.

-29 Mantel N: Evaluation of survival data and two new rank order statistics arising in its consideration. Cancer Chemother Rep 1966;50:163-170. Gill RD: Multistate life-tables and regression models. Math Popul Stud 1992;3:259-276. Kager L, Zoubek A, Potschger U, Kastner U, Flege S, Kempf-Bielack B, Branscheid D, Kotz R, SalzerKuntschik M, Winkelmann W, Jundt G, Kabisch H, Reichardt P, Jurgens H, Gadner H, Bielack SS; Cooperative German-Austrian-Swiss Osteosarcoma Study Group: Primary metastatic osteosarcoma: presentation and outcome of patients treated on neoadjuvant Cooperative Osteosarcoma Study Group protocols. J Clin Oncol 2003;21:2011-2018.

-32 Geller DS, Gorlick R: Osteosarcoma: a review of diagnosis, management, and treatment strategies. Clin Adv Hematol Oncol 2010;8:705-718.

33 Kempf-Bielack B, Bielack SS, Jurgens H, Branscheid D, Berdel WE, Exner GU, Gobel U, Helmke K, Jundt G, Kabisch H, Kevric M, Klingebiel T, Kotz R, Maas R, Schwarz R, Semik M, Treuner J, Zoubek A, Winkler K: Osteosarcoma relapse after combined modality therapy: an analysis of unselected patients in the Cooperative Osteosarcoma Study Group (COSS). J Clin Oncol 2005;23:559-568.

-34 Carrle D, Bielack S: Osteosarcoma lung metastases detection and principles of multimodal therapy. Cancer Treat Res 2009;152:165-184.

-35 Hoefnagel CA, Bruning PF, Cohen P, Marcuse HR, van der Schoot JB: Detection of lung metastases from osteosarcoma by scintigraphy using ${ }^{99} \mathrm{mTc}$-methylene diphosphonate. Diagn Imaging 1981;50:277284.

-36 Guo W, Tang XD, Tang S, Yang Y: Preliminary report of combination chemotherapy including Arsenic trioxide for stage III osteosarcoma and Ewing sarcoma. Zhonghua Wai Ke Za Zhi 2006;44:805-808.

37 Kager L, Potschger U, Bielack S: Review of mifamurtide in the treatment of patients with osteosarcoma. Ther Clin Risk Manag 2010;6:279-286. Emadi A, Gore SD: Arsenic trioxide - an old drug rediscovered. Blood Rev 2010;24:191-199.

-39 Raju GP: Arsenic: a potentially useful poison for Hedgehog-driven cancers. J Clin Invest 2011;121:1416. 


\section{Case Reports in Oncology}

Xie et al.: Effects of Arsenic Trioxide on Minor Progressive High-Grade Osteosarcoma of the Extremities Metastatic to the Lung

40 Liu B, Pan S, Dong X, Qiao H, Jiang H, Krissansen GW, Sun X: Opposing effects of arsenic trioxide on hepatocellular carcinomas in mice. Cancer Sci 2006;97:675-681.

41 Zhao H, Guo W, Peng C, Ji T, Lu X: Arsenic trioxide inhibits the growth of adriamycin resistant osteosarcoma cells through inducing apoptosis. Mol Biol Rep 2010;37:2509-2515.

42 Mialou V, Philip T, Kalifa C, Perol D, Gentet JC, Marec-Berard P, Pacquement H, Chastagner P, Defaschelles AS, Hartmann 0: Metastatic osteosarcoma at diagnosis: prognostic factors and long-term outcome - the French pediatric experience. Cancer 2005;104:1100-1109.

43 Harting MT, Blakely ML, Jaffe N, Cox CS Jr, Hayes-Jordan A, Benjamin RS, Raymond AK, Andrassy RJ, Lally KP: Long-term survival after aggressive resection of pulmonary metastases among children and adolescents with osteosarcoma. J Pediatr Surg 2006;41:194-199.

44 Chen YB, Hahn LJ, Yao YT: Long-term survival of mandibular osteosarcoma. Br J Plast Surg 1999;52:243-244.

45 Shibamoto Y, Horii N, Takahashi M: Long-term control of multiple lung metastases from osteosarcoma obtained by conventional radiotherapy: a case report. Oncol Rep 1999;6:1085-1087.

46 Wahl RL, Jacene H, Kasamon Y, Lodge MA: From RECIST to PERCIST: Evolving considerations for PET response criteria in solid tumors. J Nucl Med 2009;50(suppl 1):122S-150S.

47 Grignani G, Palmerini E, Dileo P, Asaftei SD, D’Ambrosio L, Pignochino Y, Mercuri M, Picci P, Fagioli F, Casali PG, Ferrari S, Aglietta M: A phase II trial of sorafenib in relapsed and unresectable high-grade osteosarcoma after failure of standard multimodal therapy: an Italian Sarcoma Group study. Ann Oncol 2012;23:508-516.

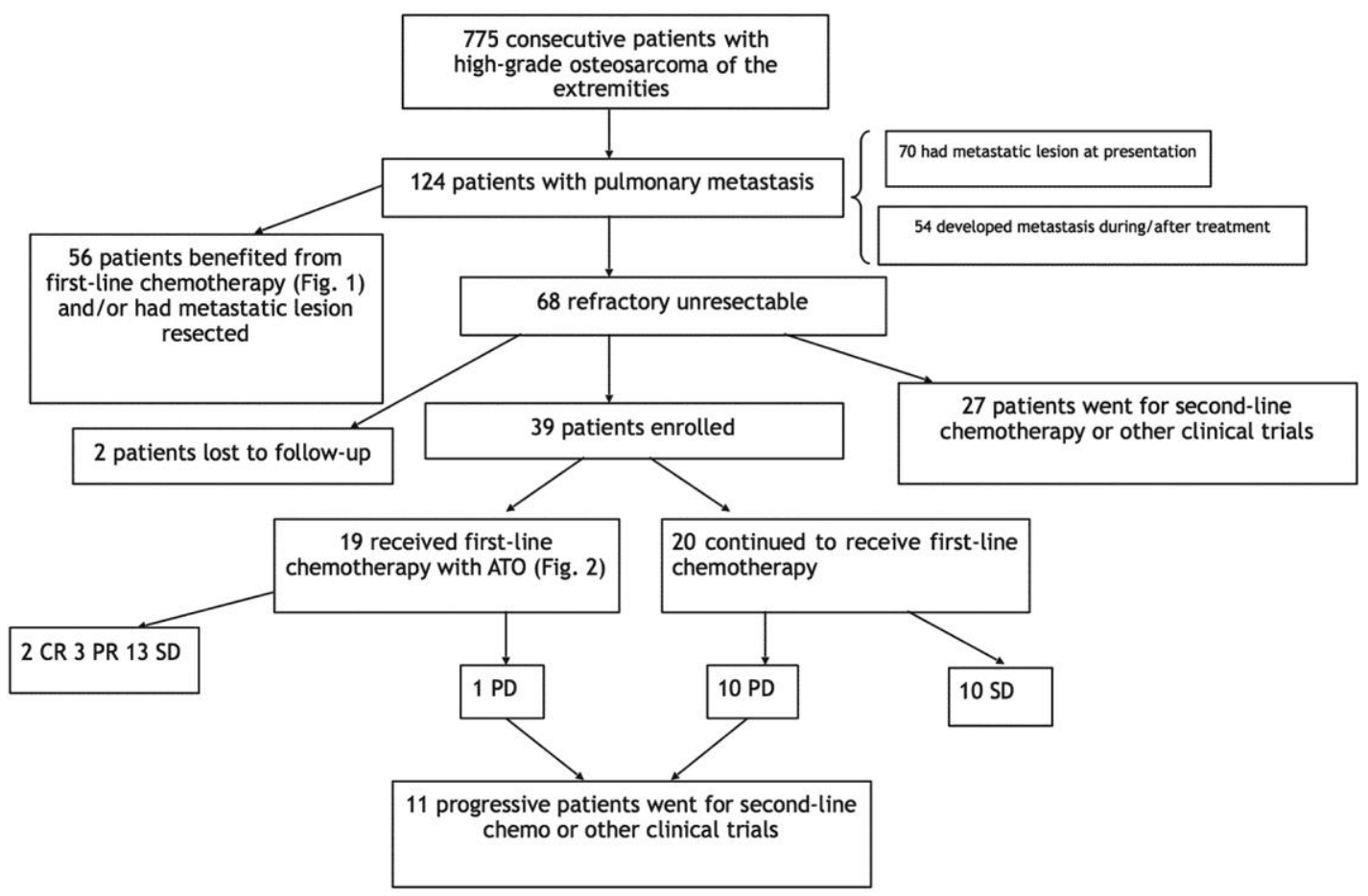

Fig. 1. Main diagram manifesting all patients who participated in this trial. $\mathrm{PD}=$ Progressive disease. 


\section{Case Reports in Oncology}

Xie et al.: Effects of Arsenic Trioxide on Minor Progressive High-Grade Osteosarcoma of the Extremities Metastatic to the Lung

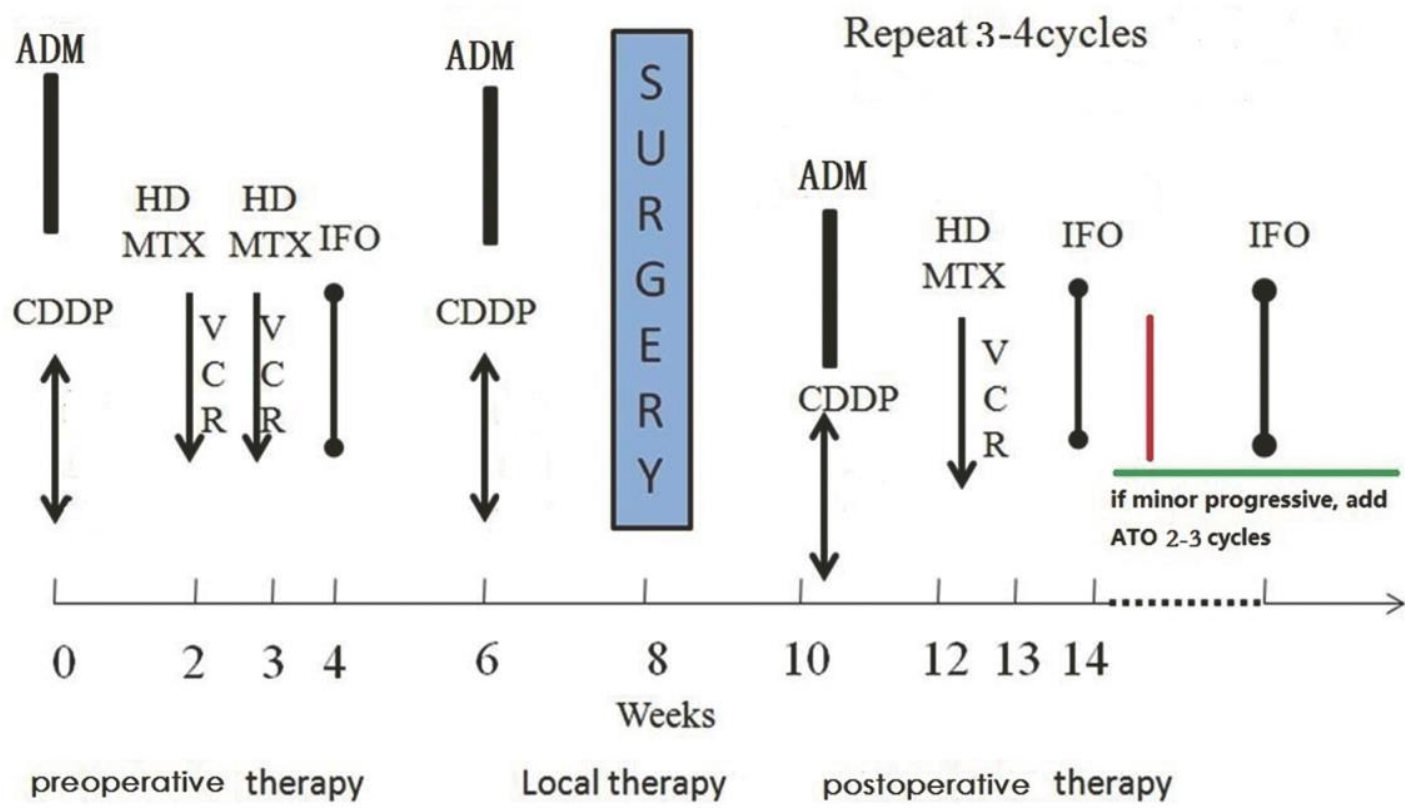

Fig. 2. Therapeutic protocol for the research group who received first-line chemotherapy with ATO. Doses administered were: doxorubicin (ADM): $60 \mathrm{mg} / \mathrm{m}^{2}$; cisplatin (CDDP): 100-120 mg/m²; ifosfamide (IFO): $2.4 \mathrm{~g} / \mathrm{m}^{2} /$ day on days 1-5; ATO: $10 \mathrm{mg}$ (5 mg) on days 1-28; methotrexate (MTX): 8-12 g/m²; leucovorin: 12-15 mg i.m. every $6 \mathrm{~h}$ for 12 doses - start $18 \mathrm{~h}$ from high-dose methotrexate (HDMTX). 


\section{Case Reports in Oncology}

Xie et al.: Effects of Arsenic Trioxide on Minor Progressive High-Grade Osteosarcoma of the Extremities Metastatic to the Lung

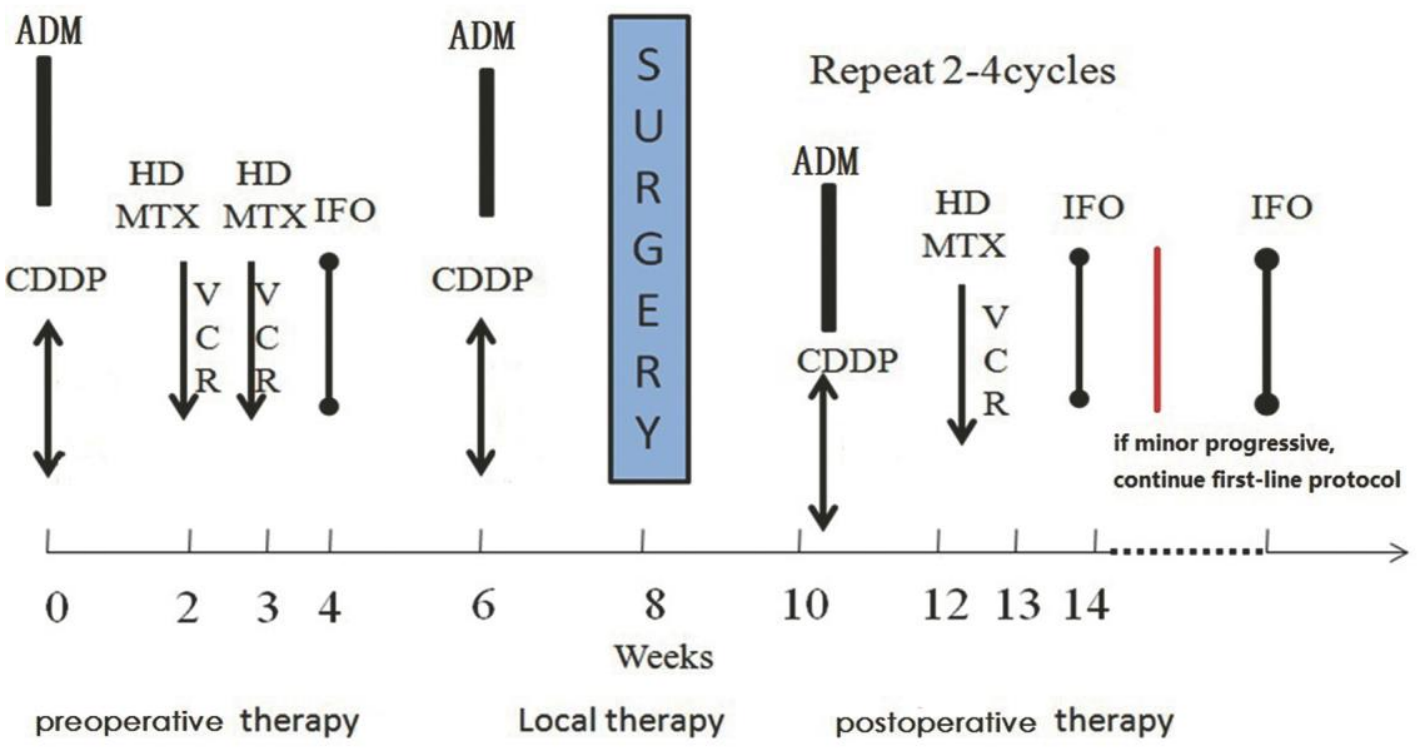

Fig. 3. Therapeutic protocol for the control group who received first-line chemotherapy alone. Doses administered were: doxorubicin (ADM): $60 \mathrm{mg} / \mathrm{m}^{2}$; cisplatin (CDDP): 100-120 mg/m²; ifosfamide (IFO): $2.4 \mathrm{~g} / \mathrm{m}^{2} /$ day on days 1-5; methotrexate (MTX): 8-12 g/m²; leucovorin: 12-15 mg i.m. every $6 \mathrm{~h}$ for 12 doses - start $18 \mathrm{~h}$ from high-dose methotrexate (HDMTX). 


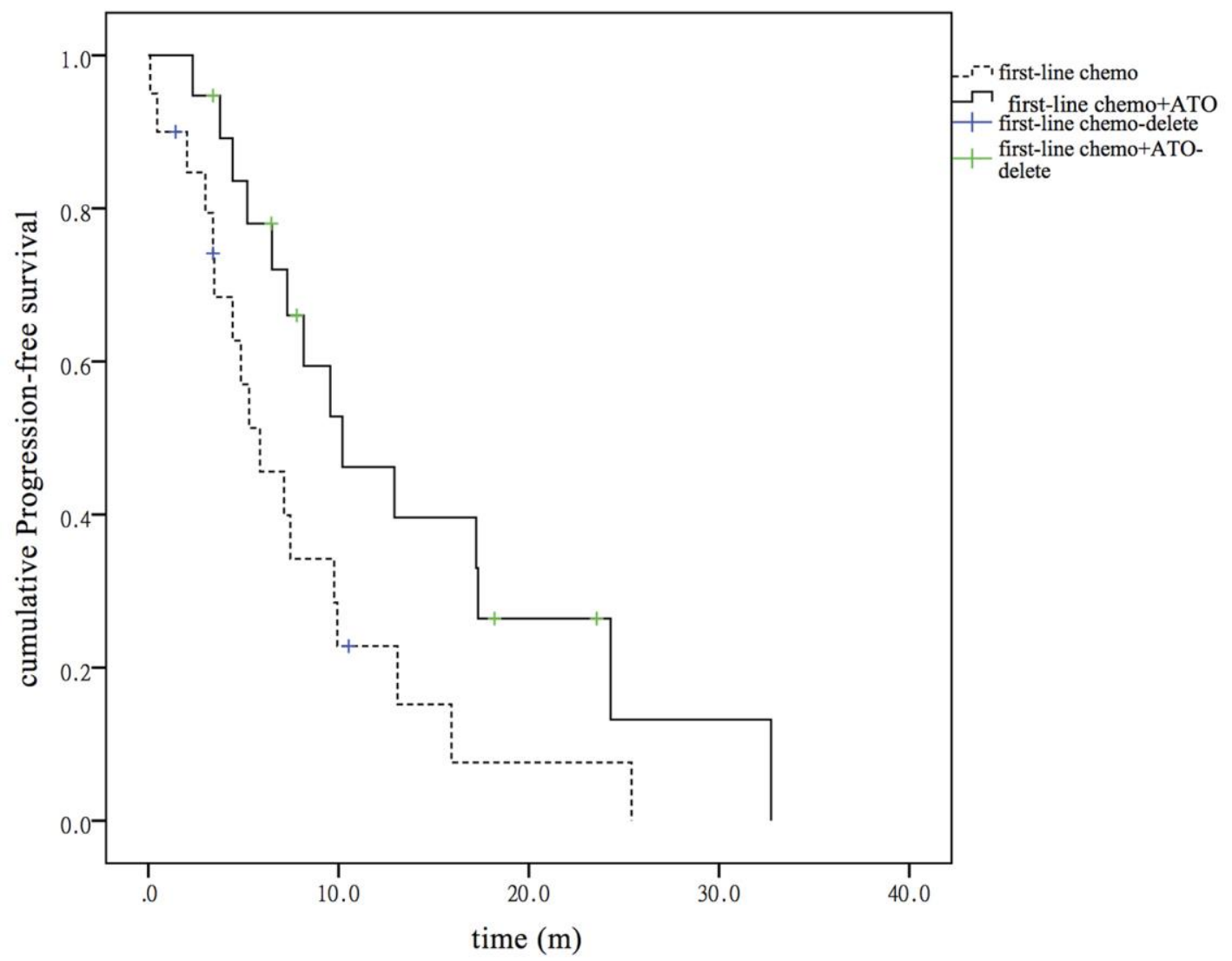

Fig. 4. PFS for the two patient groups.

Xie et al.: Effects of Arsenic Trioxide on Minor Progressive High-Grade Osteosarcoma of

the Extremities Metastatic to the Lung

(C) 2016 The Author(s). Published by S. Karger AG, Basel www.karger.com/cro 


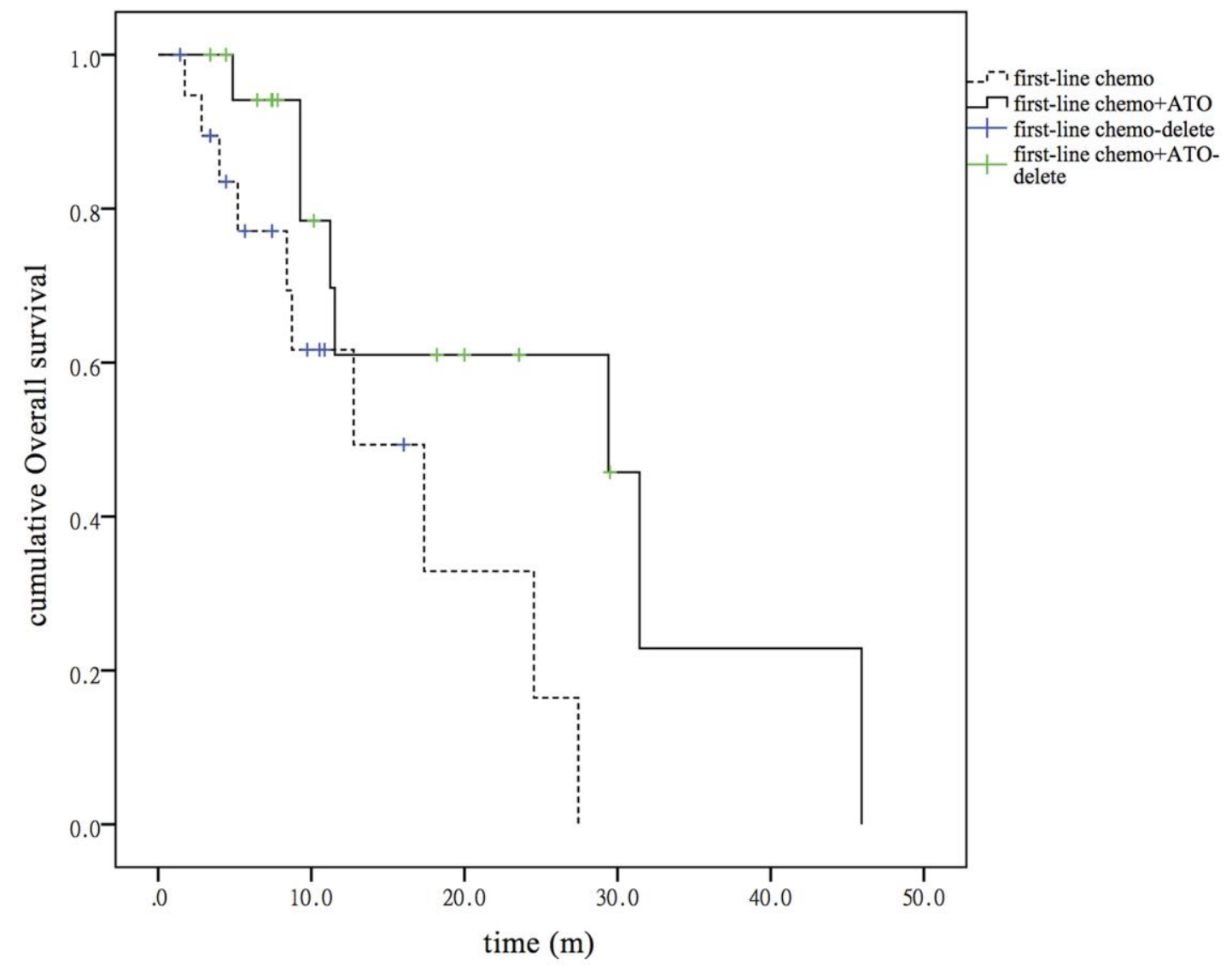

Fig. 5. OS for the two patient groups.

Xie et al.: Effects of Arsenic Trioxide on Minor Progressive High-Grade Osteosarcoma of the Extremities Metastatic to the Lung 


\section{Case Reports in Oncology}

Xie et al.: Effects of Arsenic Trioxide on Minor Progressive High-Grade Osteosarcoma of the Extremities Metastatic to the Lung

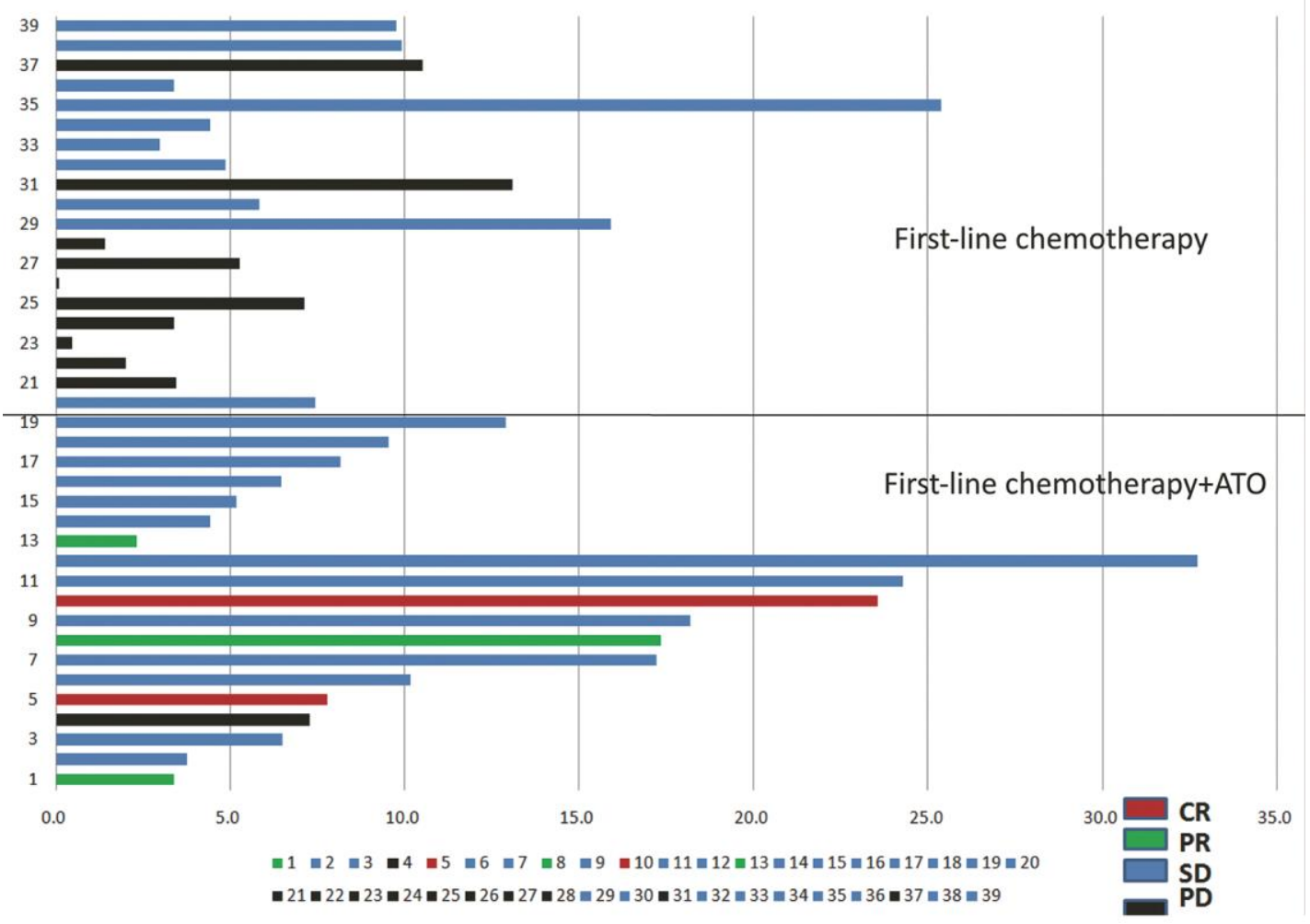

Fig. 6. Therapeutic effect of all patients who participated in the study $(n=39)$. 


\section{Case Reports in Oncology}

Case Rep Oncol 2016;9:610-628
\begin{tabular}{l|l} 
DOI: $10.1159 / 000448705$ & $\begin{array}{l}\text { C } 2016 \text { The Author(s). Published by S. Karger AG, Basel } \\
\text { www.karger.com/cro }\end{array}$ \\
\hline
\end{tabular}

Xie et al.: Effects of Arsenic Trioxide on Minor Progressive High-Grade Osteosarcoma of the Extremities Metastatic to the Lung
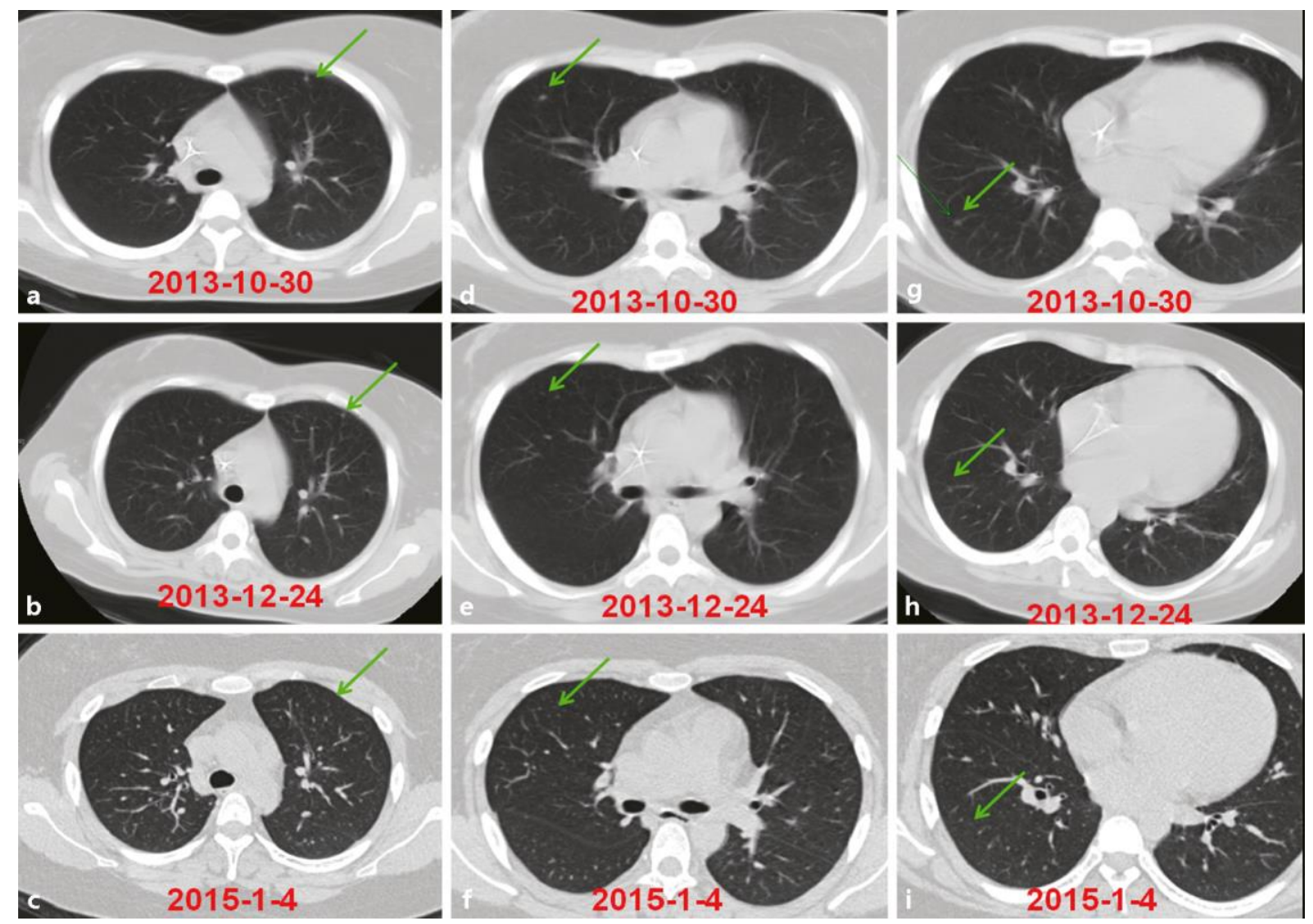

Fig. 7. Chest CT of a patient (No. 10), with CR for more than a year, showed multiple pulmonary mininodules disappearing after treatment. a-c One nodule (arrow) located at the middle left lobe which disappeared 1 year and 2 months after therapy. d-f Another nodule (arrow) located at the middle right lobe which disappeared after therapy. g-i Another nodule (arrow) from the same person with CR after therapy. 


\section{Case Reports in Oncology}

Table 1. Characteristics of patients $(n=39)$ who participated in this research

\begin{tabular}{|c|c|c|c|}
\hline Characteristics & $\mathrm{n}$ & $\%$ & $\mathrm{P}(\mathrm{PFS})$ \\
\hline Age at study entry, years (range) & \multicolumn{2}{|c|}{$17(6-55)$} & 0.193 \\
\hline \multicolumn{3}{|l|}{ Gender } & 0.475 \\
\hline Male & 22 & 56.4 & \\
\hline Female & 17 & 43.6 & \\
\hline \multicolumn{3}{|l|}{ ECOG performance status } & 0.553 \\
\hline 0 & 24 & 61.5 & \\
\hline 1 & 15 & 38.5 & \\
\hline \multicolumn{3}{|l|}{ Location of primary tumor } & 0.014 \\
\hline Distal femur & 20 & 51.3 & \\
\hline Proximal tibia and/or fibula & 8 & 20.5 & \\
\hline Humerus & 4 & 10.3 & \\
\hline Proximal femur & 4 & 10.3 & \\
\hline Others & 3 & 7.6 & \\
\hline \multicolumn{3}{|l|}{ Osteosarcoma histotype } & 0.106 \\
\hline Conventional & 31 & 79.5 & \\
\hline Teleangiectatic & 2 & 5.1 & \\
\hline Small cell & 5 & 12.8 & \\
\hline Mixed & 1 & 2.6 & \\
\hline \multicolumn{3}{|l|}{ Necrosis after surgery of local lesion } & 0.091 \\
\hline Poor $(<90 \%)$ & 16 & 41.0 & \\
\hline Good $(\geq 90 \%)$ & 8 & 20.5 & \\
\hline Not available or missing & 15 & 38.5 & \\
\hline \multicolumn{3}{|l|}{ Chemotherapy scheme } & 0.043 \\
\hline First-line chemotherapy + ATO & 19 & 48.7 & \\
\hline First-line chemotherapy & 20 & 51.3 & \\
\hline \multicolumn{4}{|l|}{ Time to progression } \\
\hline First-line chemotherapy + ATO, months (IQR) & \multicolumn{3}{|c|}{$10.2(6.5-24.3)$} \\
\hline First-line chemotherapy, months (IQR) & \multicolumn{2}{|c|}{$5.9(3.4-9.9)$} & \\
\hline \multicolumn{4}{|l|}{ Follow-up } \\
\hline First-line chemotherapy + ATO, months (IQR) & \multicolumn{3}{|c|}{$29.4(11.2-31.4)$} \\
\hline First-line chemotherapy, months (IQR) & \multicolumn{2}{|c|}{$12.8(8.4-24.5)$} & \\
\hline \multicolumn{4}{|l|}{ Evaluation $^{1}$} \\
\hline First-line chemotherapy + ATO & 19 & 100 & \\
\hline $\mathrm{CR}$ & 2 & 10.5 & \\
\hline PR & 3 & 15.8 & \\
\hline SD & 13 & 68.4 & \\
\hline PD & 1 & 5.3 & \\
\hline First-line chemotherapy & 20 & 100 & \\
\hline SD & 10 & 50 & \\
\hline PD & 10 & 50 & \\
\hline \multicolumn{4}{|l|}{ Follow-up status } \\
\hline NED & 1 & 2.5 & \\
\hline AWD & 20 & 51.3 & \\
\hline DOD & 18 & 46.2 & \\
\hline
\end{tabular}

Xie et al.: Effects of Arsenic Trioxide on Minor Progressive High-Grade Osteosarcoma of the Extremities Metastatic to the Lung 


\section{Case Reports in Oncology}

Case Rep Oncol 2016;9:610-628

DOI: $10.1159 / 000448705$

(C)

(C) 2016 The Author(s). Published by S. Karger AG, Basel www.karger.com/cro

Xie et al.: Effects of Arsenic Trioxide on Minor Progressive High-Grade Osteosarcoma of the Extremities Metastatic to the Lung

\begin{tabular}{llcc} 
Yes & 10 & 25.6 & \\
No & 29 & 74.4 & \\
\hline Disease-free interval, months & 39 & 100 & 0.012 \\
Median (IQR) & $5.3(1.5-9.8)$ & & \\
\hline
\end{tabular}

Data are n (\%) or median (range; IQR). ECOG = Eastern Cooperative Oncology Group; PD = progressive disease; NED = no evidence of disease; $\mathrm{AWD}=$ alive with disease; $\mathrm{DOD}=$ died of disease.

${ }^{1}$ According to the lesion evaluation description given in Materials and Methods.

Table 2. Comparison with historical large-scale clinical research on the treatment strategy of metastatic osteosarcoma

\begin{tabular}{|c|c|c|c|c|c|c|c|}
\hline Authors & Institution & Year & Patient group & Patients, $\mathrm{n}$ & Therapeutic strategy & $\begin{array}{l}\text { 2-year } \\
\text { OS, \% }\end{array}$ & $\begin{array}{l}\text { 5-year } \\
\text { OS, \% }\end{array}$ \\
\hline Bacci et al. & Rizzoli & 2003 & $\begin{array}{l}\text { metastasis at presen- } \\
\text { tation }\end{array}$ & 57 & $\begin{array}{l}\text { first-line chemotherapy + } \\
\text { surgery }\end{array}$ & 53 & \\
\hline Bacci et al. & Rizzoli & 2005 & $\begin{array}{l}\text { recurrent } \\
\text { osteosarcoma }\end{array}$ & 235 & $\begin{array}{l}\text { surgery and second-line che- } \\
\text { motherapy + surgery and only } \\
\text { second-line chemotherapy or } \\
\text { radiotherapy }\end{array}$ & & 28.7 \\
\hline Kempf-Bielack et al. & COSS & 2005 & $\begin{array}{l}\text { recurrent } \\
\text { osteosarcoma }\end{array}$ & 576 & not standardized & 38 & 23 \\
\hline Harting et al. & $\begin{array}{l}\text { University of } \\
\text { Texas Medical } \\
\text { Sciences Center } \\
\end{array}$ & 2006 & $\begin{array}{l}\text { recurrence with lung } \\
\text { metastasis }\end{array}$ & 137 & mainly surgery & & 29 \\
\hline Bacci et al. & Rizzoli & 2008 & $\begin{array}{l}\text { metastasis at presen- } \\
\text { tation }\end{array}$ & 162 & $\begin{array}{l}\text { first-line chemotherapy + } \\
\text { surgery }\end{array}$ & & 19.1 \\
\hline Steliga and Vaporciyan & IRLM & 2009 & $\begin{array}{l}\text { recurrence with lung } \\
\text { metastasis }\end{array}$ & 734 & mainly surgery & & 36 \\
\hline $\begin{array}{l}\text { Briccoli } \\
\text { et al. }\end{array}$ & Rizzoli & 2010 & $\begin{array}{l}\text { recurrence with lung } \\
\text { metastasis }\end{array}$ & 323 & mainly surgery & & 37 \\
\hline$\overline{\text { Gelderblom et al. }}$ & $\begin{array}{l}\text { UK/MRC } \\
\text { EORTC/SIOP } \\
\text { other }\end{array}$ & 2011 & $\begin{array}{l}\text { recurrent } \\
\text { osteosarcoma }\end{array}$ & 1,067 & not standardized & & 18 \\
\hline Present study & $\begin{array}{l}\text { Musculoskeletal } \\
\text { Tumor Center of } \\
\text { PKUPH }\end{array}$ & 2015 & $\begin{array}{l}\text { recurrence with lung } \\
\text { metastasis }\end{array}$ & $\begin{array}{l}19 \\
20\end{array}$ & $\begin{array}{l}\text { first-line chemotherapy + ATO } \\
\text { first-line chemotherapy }\end{array}$ & $\begin{array}{r}61 \\
16.4\end{array}$ & \\
\hline
\end{tabular}

